\title{
Candiduria-Study of Virulence Factors and Its Antifungal Susceptibility Pattern in Tertiary Care Hospital
}

\author{
Subramanian Pramodhini ${ }^{1}$ Sreenivasan Srirangaraj ${ }^{1} \quad$ Joshy Maducolil Easow ${ }^{1}$ \\ ${ }^{1}$ Department of Microbiology, Mahatma Gandhi Medical College \\ and Research Institute, Sri Balaji Vidyapeeth (deemed to be \\ university), Puducherry, India \\ Address for correspondence Subramanian Pramodhini, MD, \\ Department of Microbiology, Mahatma Gandhi Medical College and \\ Research Institute, Sri Balaji Vidyapeeth (deemed to be university), \\ Pondicherry 607403, India (e-mail: pramodhinis@gmail.com).
}

J Lab Physicians 2021;13:231-237.

\begin{abstract}
Keywords

- virulence

- biofilm

- proteinase

- phospholipase

- hemolysin

Background The increased incidence of candiduria in hospitalized patients is due to the use of indwelling devices, long-term antibiotics, parenteral nutrition, and immunocompromised status of the patient. In this study, an attempt was made to speciate, characterize, and determine the antifungal susceptibility pattern of Candida isolated from urinary tract infections (UTIs).

Materials and Methods A total of 70 Candida isolates were obtained from urine samples. The isolated Candida species were studied for the production of virulence factors like phospholipase, protease activities, hemolysin, and biofilm production. Antifungal susceptibility testing of the isolated yeasts was done using Mueller-Hinton agar supplemented with $0.5 \mathrm{mg} / \mathrm{mL}$ methylene blue by E-test method for amphotericin B, fluconazole, caspofungin, and voriconazole.

Results Out of 70 isolates, Candida tropicalis was the most frequently isolated species (65.7\%), followed by Candida albicans (14.3\%), Candida glabrata (7.1\%), Candida krusei (5.7\%), Candida parapsilosis (4.3\%), and Candida dubliniensis (2.9\%). A total of $37.1 \%$ were biofilm producers, $62.9 \%$ showed proteinase activity, $38.6 \%$ were phospholipase positive, and $58.6 \%$ isolates showed hemolytic activity. Antifungal susceptibility profile of Candida species showed 38.6, 25.7, 15.7, and $12.9 \%$ resistance to amphotericin B, fluconazole, caspofungin, and voriconazole, respectively.

Conclusion A rising trend in isolation of non-albicans Candida from urinary isolates was noticed, which was statistically significant when comparing catheterized and noncatheterized urinary isolates from our study. However, there was no statistically significant difference when different virulence factor expressions were compared among Candida spp. isolated from catheterized and noncatheterized urinary samples. Due to this rise in non-albicans Candida species causing UTI that are intrinsically resistant to certain antifungal agents like azoles and increasing incidence of antifungal resistance, it is essential to monitor the antifungal susceptibility profile of Candida species causing candiduria.
\end{abstract}

published online June 28, 2021
DOI https://doi.org/

10.1055/s-0041-1730880 ISSN 0974-2727 (c) 2021. The Indian Association of Laboratory Physicians.

This is an open access article published by Thieme under the terms of the Creative Commons Attribution-NonDerivative-NonCommercial-License, permitting copying and reproduction so long as the original work is given appropriate credit. Contents may not be used for commercial purposes, or adapted, remixed, transformed or built upon. (https://creativecommons.org/licenses/by-nc-nd/4.0/). Thieme Medical and Scientific Publishers Pvt. Ltd. A-12, 2nd Floor, Sector 2, Noida-201301 UP, India 


\section{Introduction}

Candiduria, by definition, is the presence of yeast cells in urine. There is a rising trend of candiduria in hospitalized patients, due to the increased use of indwelling devices, parenteral nutrition, broad spectrum antibiotics, and chemotherapeutic agents. ${ }^{1}$ Majority of patients diagnosed with candiduria do not manifest any symptoms and it is indeed very difficult to differentiate between bacteriuria and candiduria in symptomatic patients. In intensive care unit patients, presence or absence of symptoms should not be neglected, as candiduria are considered as one of the marker for invasive candidiasis. In addition, the expression of various virulence factors like proteinase, phospholipase, hemolysin and biofilm formation contributes to the pathogenicity of Candida spp. Identification of Candida species is very crucial for the administration of antifungals due to the intrinsic resistance of non-albicans Candida to azoles. In this study, an attempt was made to speciate, to study the virulence factors, and to determine the antifungal susceptibility pattern of Candida isolated from urinary tract infections (UTIs).

\section{Materials and Methods}

This prospective analytical study for a period of 1 year was conducted from a single center in a tertiary care hospital in South India. A total of 70 Candida spp. were studied from urine samples either mid stream urine or catheterized from OPD, wards, or ICU patients, which were sent to the microbiology laboratory for fungal culture and sensitivity. The inclusion criteria for the study were that the patients were above 18 years of age, Candida isolated as a pure growth with a significant colony count of $\geq 10^{4}$ colony forming units (CFUs)/mL of urine, isolates where direct microscopic examination showed concomitant pyuria, and isolates recovered from the second sample of the same patient. Absence of pyuria or mixed growth was excluded from our study. This study was done after approval by Institutional Ethical committee.

The urine samples obtained were immediately processed in the microbiology laboratory by semiquantitative method as per standard procedures. For fungal culture, samples were inoculated on to Sabouraud dextrose agar (SDA) and incubated at $25^{\circ} \mathrm{C}$. Identification of the growth on SDA plates was done by colony morphology, Gram-staining, and standard biochemical reactions. ${ }^{2}$ Chromogenic Agar (HiMedia) was used to identify Candida species ( - Fig. 1). Speciation of Candida isolates was done by testing for germ tube formation, growth on corn meal agar, sugar assimilation, and sugar fermentation tests. ${ }^{3}$

Candida isolates were studied for the production of virulence factors like phospholipase, protease activity, hemolysin, and biofilm production by following methods:

\section{Phospholipase Activity Detection}

After the inoculum showed growth on egg yolk agar, detection of Candidal phospholipase activity was done measuring the zone of precipitation. The organism was considered to be positive for phospholipase activity, if they produce a zone of

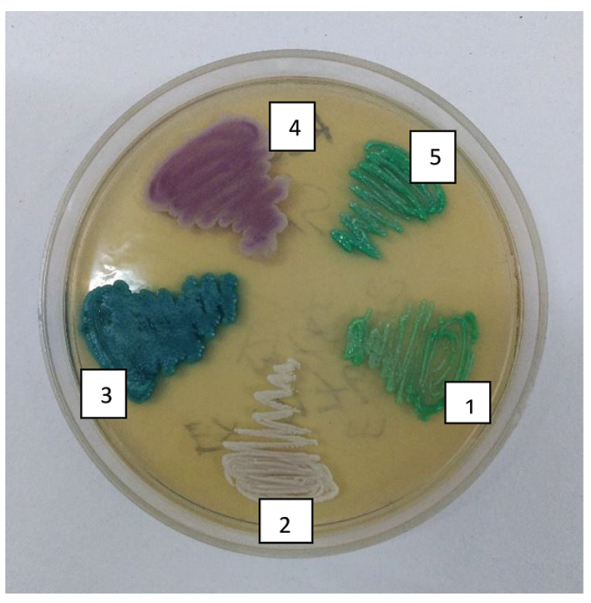

1-Candida albicans 2-Candida parapsilosis 3-Candida tropicalis 4- Candida krusei 5-Candida dubliensis

Fig. 1 Growth of Candida spp. on Hicrome Agar.

precipitation surrounding the colony. The ratio of the diameter of the colony to the total diameter of the precipitation zone (including the colony) is measured as the value of phospholipase activity (Pz). If the measured value of $\mathrm{Pz}$ value is less than one of $1(\mathrm{Pz}<1)$, it indicates positive phospholipase activity and Pz value equal to 1 means no phospholipase activity (-Fig. 2). Candida albicans-reference strains (ATCC 10231 and ATCC 24433) were the positive controls. ${ }^{4-6}$

\section{Proteinase Activity Determination}

Measurement of Candidal extracellular proteinase activity was done as per the technique described by Staib, ${ }^{7}$ using bovine serum albumin. Degradation of the protein was determined when an opaque zone was seen around the colony that was unstainable with amido black.

Calculation of proteinase activity (Prz) was done by measuring the ratio of the colony to the diameter of the proteolytic unstained zone. A Prz value corresponding to one signified no activity, and value less than one meant positive proteinase activity. C. albicans reference strains (ATCC 10231 and ATCC 10261) were the positive controls.

\section{Hemolysin Activity Determination}

Evaluation of hemolysin activity was done by a blood plate assay as explained by Manns et al. $^{8}$ The ratio of the diameter of the colony to that of the translucent zone of hemolysis (in $\mathrm{mm}$ ) around the colony was determined as the hemolytic index (Hz value). C. albicans (ATCC 90028) was used as the positive control (see - Fig. 3 ). ${ }^{4,8}$

\section{Detection of Biofilm Production}

Biofilm formation was detected by method proposed by Branchini and Pfaller.9 A loopful of colony from SDA plate was inoculated into $10 \mathrm{~mL}$ of Sabouraud liquid broth with $8 \%$ glucose supplemented and kept for incubation at $37^{\circ} \mathrm{C}$ for 48 hours. Following this, the broth was aspirated from the tube and the walls were stained using Safranin. Biofilm formation was graded as negative $(0+)$ or $1+, 2+$, and $3+$ 
corresponding with weak, moderate, and strong positivity (-Fig. 4).

\section{Antifungal Susceptibility Testing}

Antifungal susceptibility testing of the isolated yeasts was performed on Mueller-Hinton agar supplemented with $0.5 \mathrm{mg} / \mathrm{mL}$ methylene blue by E-test method (Hi-Media) for-amphotericin-B, fluconazole, caspofungin, and voriconazole. Interpretation of susceptibility was done using the breakpoint criteria defined by the CLSI document M44. ${ }^{10}$ The MIC ranges used in this study for various antifungal drugs were-amphotericin B $(0.002-32 \mu \mathrm{g} / \mathrm{mL})$, fluconazole $(0.016-256 \mu \mathrm{g} / \mathrm{mL})$, voriconazole $(0.002-32 \mu \mathrm{g} / \mathrm{mL})$, and caspofungin $(0.002-32 \mu \mathrm{g} / \mathrm{mL}$ ) (-Fig. 5).

\section{Statistical Analysis}

All data were entered into MS Excel 2010 and analyzed. Percentages were calculated for categorical variables.

\section{Results}

In this study, 70 adult patients were diagnosed with candiduria, 43 (61.4\%) of them were female and 27 (38.6\%) were male. Age group analysis showed that $12(17.1 \%)$ patients were between 18 and 30 years, 10 (14.3\%) were between 31 and 45 years, 16 (22.9\%) were between 46 and 60 years, 26 (37.1\%) were between 61 and 75 years, and 6 (8.6\%) were older than 76 years (-Table 1). Out of 70 isolates, 12 (17.1\%) were from outpatients and $58(82.8 \%)$ were isolated from inpatients. Isolated Candida spp. from catheterized and noncatheterized urine samples were found to be 30 (42.9\%) and 40 (57.1\%), respectively (-Table 2). Among 30 isolates from catheterized urine samples, 10 (33.3\%) and 20 (66.7\%) were found to be $C$. albicans and non-albicans Candida, respectively. Among 40 Candida isolates from catheterized urine samples, only 2 (5\%) were identified as C. albicans, the remaining 38 (95\%) were identified as non-albicans Candida. The predominant species isolated in our study was Candida tropicalis representing $65.7 \%$ of isolates, followed by

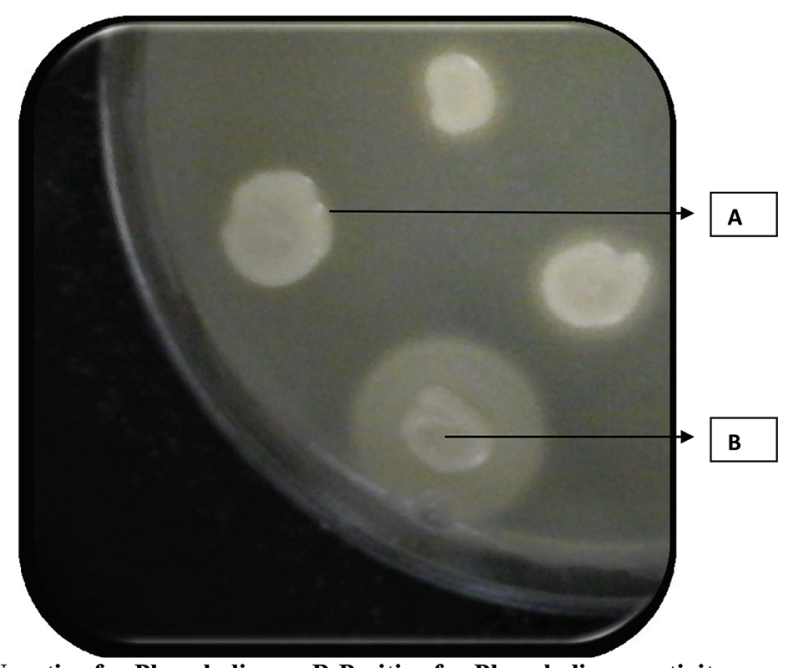

A-Negative for Phospholipase; B-Positive for Phospholipase activity

Fig. 2 Phospholipase production in Egg yolk agar.
C. albicans (14.3\%), Candida glabrata (7.1\%), Candida krusei (5.7\%), Candida parapsilosis (4.3\%), and Candida dubliniensis (2.9\%) (- Table 3). Positivity values of hemolysin, proteinase, phospholipase, and biofilm in isolates from catheterized sample were $56.7,70.0,43.3$, and $40.0 \%$, respectively, and from noncatheterized samples were around 60, 57.5, 35, and $35 \%$, respectively (-Table 4 ). Antifungal susceptibility profile of Candida species showed $38.6 \%$ were resistant to amphotericin B, $27.1 \%$ were resistant to fluconazole, $15.7 \%$ resistant to caspofungin, and $14.3 \%$ resistant to voriconazole (-Tables 5 and 6 ).

\section{Discussion}

Candiduria is rarely seen as a community-acquired infection in a structurally normal urinary tract and in healthy people. It has been increasingly reported as an important subgroup of nosocomial UTIs (10-15\%) and almost all are caused by Candida spp. ${ }^{11}$ In a recent case-controlled study, it has been shown that the risk of developing candiduria was increased 12-fold after urinary catheterization, sixfold after the use of broad spectrum antibiotics and urinary tract abnormalities, fourfold following abdominal surgeries, twofold in the presence of diabetes mellitus, and onefold on corticosteroid administration. ${ }^{12}$

In our study, majority of patients identified with candiduria were in the age group of 61 to 75 years (37.1\%), followed by 46 to 60 age group (22.9\%). Studies have shown high prevalence rate of UTIs in elderly people, which is concordant with our study.$^{13}$ However, there are studies showing higher prevalence rates in patients belonging to 51 to 60 years of age group. ${ }^{14}$

Frequency of distribution of candiduria in females (43, $61.4 \%$ ) was higher in our study when compared with males (27, 38.6\%). Several similar studies have shown female predominance in the incidence of candiduria with prevalence rates of $61.2,66.2$, and $70.2 \%$ which are in agreement with our study. ${ }^{15-17}$

In our study, non-albicans Candida spp. emerged as the predominant pathogen contributing to $82.9 \%$ of fungal UTI. Of which, C. tropicalis was most frequently isolated (65.7\%), while $C$. albicans were identified in only $17.1 \%$ of the cases. The result of the present study is in agreement with other studies, where increased prevalence of non-albicans Candida causing UTI was reported. ${ }^{18-20}$ Overall, there has been a rising trend of non-albicans Candida spp. causing candiduria, the most prevalent of which was C. tropicalis. ${ }^{18}$

On detecting candiduria, treating physicians have to decide whether it is a result of UTI (upper or lower) or bladder colonization, or urine sample contamination. Contamination can be differentiated from colonization or infection by obtaining another urine sample to verify candiduria. ${ }^{1}$

A study on the predominance of Candida species isolated, reported $C$. albicans being seen in more than $51 \%$ cases, followed by $C$. glabrata and $C$. tropicalis. ${ }^{13}$ Pathogenicity of Candida is enhanced by several virulence determinants like host surface adherence, secretion of hydrolytic enzymes, and formation of pseudohyphae. ${ }^{14}$ 
Table 1 Age and sex distribution pattern of Candida spp. from urine samples $(n=70)$

\begin{tabular}{|l|l|l|l|}
\hline Age & Male & Female & No \% \\
\hline $15-30$ & 1 & 11 & $12(17.1 \%)$ \\
\hline $31-45$ & 6 & 4 & $10(14.3 \%)$ \\
\hline $46-60$ & 6 & 10 & $16(22.9 \%)$ \\
\hline $61-75$ & 12 & 14 & $26(37.1 \%)$ \\
\hline$>76$ & 2 & 4 & $6(8.6 \%)$ \\
\hline Total & $27(38.6 \%)$ & $43(61.4 \%)$ & $70(100 \%)$ \\
\hline
\end{tabular}

Table 2 Distribution of cases among urinary isolates of Candida

\begin{tabular}{|l|l|l|l|}
\hline IP/OP & Catheterized & Noncatheterized & No (\%) \\
\hline OP & 0 & 12 & $12(17.1 \%)$ \\
\hline IP & 30 & 28 & $58(82.8 \%)$ \\
\hline Total & $30(42.9 \%)$ & $40(57.1 \%)$ & $70(100 \%)$ \\
\hline
\end{tabular}

Table 3 Percentage of distribution of urinary isolates of Candida species

\begin{tabular}{|c|c|c|c|c|c|c|c|}
\hline \multirow[t]{2}{*}{ Species } & \multicolumn{2}{|c|}{ Catheterized (30) } & \multicolumn{2}{|c|}{ Noncatheterized (40) } & \multicolumn{2}{|c|}{ Total } & \multirow[t]{2}{*}{$p$-Value } \\
\hline & No & $\%$ & No & $\%$ & No & $\%$ & \\
\hline Candida albicans & 10 & 33.3 & 2 & 5 & 12 & 17.1 & \multirow{8}{*}{$\begin{array}{l}\text { The } p \text {-value is } \\
0.001854 \text {. } \\
\text { Significant at } \\
p<0.05 \text {. }\end{array}$} \\
\hline Non-albicans Candida & 20 & 66.7 & 38 & 95 & 58 & 82.9 & \\
\hline - Candida tropicalis & 15 & 50.0 & 31 & 77.5 & 46 & 65.7 & \\
\hline - Candida glabrata & 1 & 3.3 & 3 & 7.5 & 4 & 5.7 & \\
\hline - Candida krusei & 0 & 0.0 & 3 & 7.5 & 3 & 4.3 & \\
\hline - Candida parapsilosis & 2 & 6.7 & 1 & 2.5 & 3 & 4.3 & \\
\hline - Candida dubliniensis & 2 & 6.7 & 0 & 0 & 2 & 2.9 & \\
\hline Total & 30 & 100.0 & 40 & 100 & 70 & 100 & \\
\hline
\end{tabular}

Table 4 Detection of virulence among Candida isolated from catheterized and noncatheterized urine samples

\begin{tabular}{|l|l|l|l|l|l|l|l|l|}
\hline \multirow{2}{*}{ Virulence factors } & \multicolumn{3}{|c|}{$\begin{array}{c}\text { Catheterized } \\
\text { (30) }\end{array}$} & $\begin{array}{c}\text { Noncatheterized } \\
\text { (40) }\end{array}$ & \multicolumn{3}{c|}{ Total } & p-Value \\
\cline { 2 - 10 } & Positive & $\%$ & Positive & $\%$ & No & $\%$ & p-Value & Significance \\
\hline Hemolysin & 17 & 56.7 & 24 & 60 & 41 & 58.6 & 0.779344 & $\begin{array}{l}\text { Not significant at } \\
p<0.05 .\end{array}$ \\
\hline Proteinase & 21 & 70.0 & 23 & 57.5 & 44 & 62.9 & 0.137233 & \\
\hline Phospholipase & 13 & 43.3 & 14 & 35 & 27 & 38.6 & 00.47843 & \\
\hline Biofilm & 12 & 40.0 & 14 & 35 & 26 & 37.1 & 0.668326 & \\
\hline
\end{tabular}

In the current study, a rising trend in isolation of non-albicans Candida from urinary isolates was noticed, which was statistically significant when comparing catheterized and noncatheterized urinary isolates in our study ( $p>0.05$ using Fisher's exact test). ${ }^{20,21}$

Also, owing to the problem of intrinsic resistance of some non-albicans Candida species to azole group of antifungal agents, empirical treatment of candiduria with azole group of antifungal agents would not be effective. This further validates the importance of speciation of Candida.

Virulence factors expression by Candida species contribute to the pathogenesis by secreting various hydrolytic enzymes by facilitating its adherence to host tissue, cell membranes rupture, mucosal surfaces and blood vessels invasion, and evading immune system of host. Phospholipases hydrolyses the fatty acids from phospholipids of mammalian cell membranes, thereby destabilizing the membranes, which in turn facilitate the tissue invasion and dissemination of infections. To establish their persistence and survival in the host cells, hemolysin act upon by RBC lysis and acquire elemental iron from hemoglobin. Biofilm formation is considered as one of the most important crucial virulence factors by attaching to body sites and further proliferation. Thus, virulence factors help the organisms to evade host defense mechanisms and also to establish their pathogenicity. ${ }^{21}$

In our study, proteinase activity was demonstrated in $62.9 \%$ of the isolates, $58.6 \%$ showed hemolysin positivity, phospholipase activity in $38.6 \%$ isolates, and $37.1 \%$ were biofilm producers. Study by Alenzi, ${ }^{22}$ on the virulence factor of urinary isolates of Candida showed similar percentage 
Table 5 Antifungal susceptibility profiles of Candida species isolated from urine $(n=70)$

\begin{tabular}{|c|c|c|c|c|c|c|}
\hline \multirow[t]{2}{*}{ Candida species } & \multicolumn{3}{|c|}{ MIC interpretative value } & \multicolumn{3}{|c|}{ Observation } \\
\hline & $S$ & SDD or I & $R$ & $S \%$ & SDD or I (\%) & $R(\%)$ \\
\hline \multicolumn{7}{|l|}{ Candida tropicalis (46) } \\
\hline Amphotericin B & $\leq 1$ & & $\geq 2$ & 31 & & 15 \\
\hline Fluconazole & $\leq 2$ & 4 & $\geq 8$ & 30 & 4 & 12 \\
\hline Voriconazole & $\leq 0.12$ & $0.25-0.5$ & $\geq 1$ & 41 & 2 & 3 \\
\hline Caspofungin & $\leq 0.25$ & 0.5 & $\geq 1$ & 38 & 2 & 6 \\
\hline \multicolumn{7}{|l|}{ Candida albicans (10) } \\
\hline Amphotericin B & $\leq 1$ & & $\geq 2$ & 8 & & 2 \\
\hline Fluconazole & $\leq 2$ & 4 & $\geq 8$ & 7 & 3 & 0 \\
\hline Voriconazole & $\leq 0.12$ & $0.25-0.5$ & $\geq 1$ & 8 & 2 & 0 \\
\hline Caspofungin & $\leq 0.25$ & 0.5 & $\geq 1$ & 9 & & 1 \\
\hline \multicolumn{7}{|l|}{ Candida glabrata (5) } \\
\hline Amphotericin B & $\leq 1$ & & $\geq 2$ & 2 & & 3 \\
\hline Fluconazole & $\leq 8$ & $16-32$ & $\geq 64$ & 2 & 2 & 1 \\
\hline Voriconazole & 0 & 0 & 0 & - & & - \\
\hline Caspofungin & $\leq 0.12$ & $0.25-0.5$ & $\geq 1$ & 2 & 1 & 2 \\
\hline \multicolumn{7}{|l|}{ Candida krusei (4) } \\
\hline Amphotericin B & $\leq 1$ & & $\geq 2$ & 1 & & 3 \\
\hline Fluconazole & 0 & 0 & 0 & - & & - \\
\hline Voriconazole & $\leq 0.5$ & 1 & $\geq 2$ & 0 & & 4 \\
\hline Caspofungin & $\leq 0.25$ & 0.5 & $\geq 1$ & 2 & 1 & 1 \\
\hline \multicolumn{7}{|c|}{ Candida parapsilosis (3) } \\
\hline Amphotericin B & $\leq 1$ & & $\geq 2$ & 1 & & 2 \\
\hline Fluconazole & $\leq 2$ & 4 & $\geq 8$ & 2 & & 1 \\
\hline Voriconazole & $\leq 0.12$ & $0.25-0.5$ & $\geq 1$ & 2 & 1 & 0 \\
\hline Caspofungin & $\leq 2$ & 4 & $\geq 8$ & 2 & & 1 \\
\hline \multicolumn{7}{|c|}{ Candida dubliniensis (2) } \\
\hline Amphotericin B & $\leq 1$ & & $\geq 2$ & 0 & & 2 \\
\hline Fluconazole & $\leq 2$ & 4 & $\geq 8$ & 1 & & 1 \\
\hline Voriconazole & $\leq 0.12$ & $0.25-0.5$ & $\geq 1$ & 1 & & 1 \\
\hline Caspofungin & $\leq 0.25$ & 0.5 & $\geq 1$ & 1 & 1 & 0 \\
\hline
\end{tabular}

Abbreviations: MIC, minimum inhibitory concentration; SDD, susceptible-dose-dependent.

of expression of virulence factors for biofilm and phospholipase activity, except for proteinase activity, which was on higher rate in our study. Proteinases degrade host epithelial and mucosal barrier proteins including keratin, collagen, and mucin. These help Candida in resisting the cellular and humoral components of the host immunity by degrading antibodies, complement, and cytokines. ${ }^{23}$

In a different study by Sachin et $\mathrm{al}^{24}$ phospholipase, proteinase, and hemolysin activity was seen in 60.9, 59.1, and $51.8 \%$ of Candida isolates, respectively. A similar study by Udayalaxmi et $\mathrm{al}^{25}$ among urinary isolates of Candida detected that $50 \%$ of their isolates were biofilm producers, 97.6\% were hemolysin positive, and $37.1 \%$ showed phospholipase activity. The difference in the virulence factor expression among clinical isolates of Candida depends on various factors such as the infecting Candida species, geographical region, infection site type, and stage of infection as well as host immunity. A comparative study of different virulence factors expression among Candida spp. isolated from catheterized and noncatheterized urinary samples showed no statistically relevant difference in the production of virulence factors such as hemolysin, phospholipase, proteinase, and biofilm producers. Thus virulence factor expression is influenced by various other contributing factors such as infecting species, geographical origin, type, site and stage of infection, underlying risk factors, comorbidities, and host immune response.

In our study, antifungal susceptibility profile of Candida species showed 27 (38.6\%), 19 (22.7\%), 11 (15.7\%), and 
Table 6 Overall susceptibility pattern of Candida species isolated from urine $(n=70)$

\begin{tabular}{|c|c|c|c|c|c|c|c|c|}
\hline \multirow[t]{2}{*}{ Candida species } & \multicolumn{2}{|c|}{ Amphotericin B } & \multicolumn{2}{|c|}{ Caspofungin } & \multicolumn{2}{|c|}{ Voriconazole } & \multicolumn{2}{|c|}{ Fluconazole } \\
\hline & $S$ & $\mathbf{R}$ & $\mathrm{S}$ & $\mathbf{R}$ & $S$ & $\mathbf{R}$ & $S$ & $\mathbf{R}$ \\
\hline Candida tropicalis (46) & 31 & 15 & 40 & 6 & 43 & 3 & 34 & 12 \\
\hline Candida albicans (10) & 8 & 2 & 9 & 1 & 10 & 0 & 10 & 0 \\
\hline Candida glabrata (5) & 2 & 3 & 3 & 2 & 3 & 2 & 4 & 1 \\
\hline Candida krusei (4) & 1 & 3 & 3 & 1 & 0 & 4 & 0 & 4 \\
\hline Candida parapsilosis (3) & 1 & 2 & 2 & 1 & 3 & 0 & 2 & 1 \\
\hline Candida dubliniensis (2) & 0 & 2 & 2 & 0 & 1 & 1 & 1 & 1 \\
\hline Total (70) & $\begin{array}{l}43 \\
(61.4 \%)\end{array}$ & $\begin{array}{l}27 \\
(38.6 \%)\end{array}$ & $\begin{array}{l}59 \\
(84.3 \%)\end{array}$ & $\begin{array}{l}11 \\
(15.7 \%)\end{array}$ & $\begin{array}{l}60 \\
(85.7 \%)\end{array}$ & $\begin{array}{l}10 \\
(14.3 \%)\end{array}$ & $\begin{array}{l}51 \\
(72.9 \%)\end{array}$ & $\begin{array}{l}19 \\
(27.1 \%)\end{array}$ \\
\hline
\end{tabular}

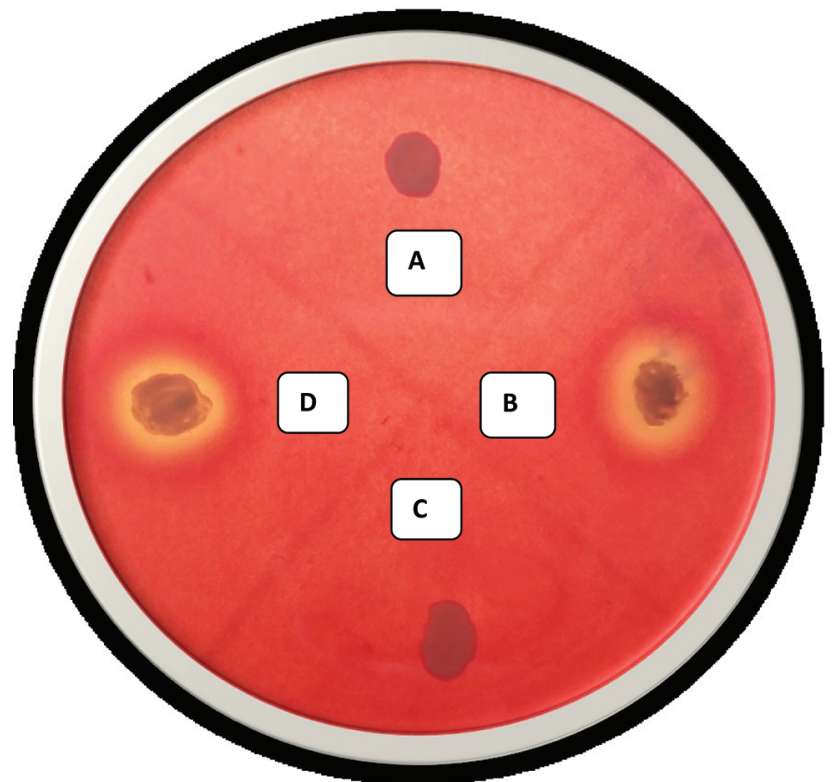

A, C -No hemolysis; B, D -Positive for hemolysin

Fig. 3 Hemolysin production of Candida spp. in Blood agar.

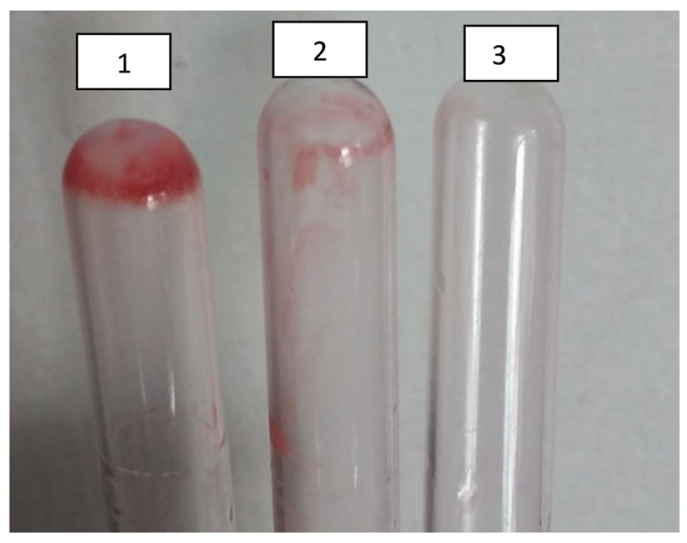

1-Strong positive

2-Weak positive

3-Negative

Fig. 4 Biofilm formation by tube adherence method.

10 (12.3\%) resistance to amphotericin B, fluconazole, caspofungin, and voriconazole, respectively. Similar percentage of resistance to fluconazole 22/90 (24.4\%) and

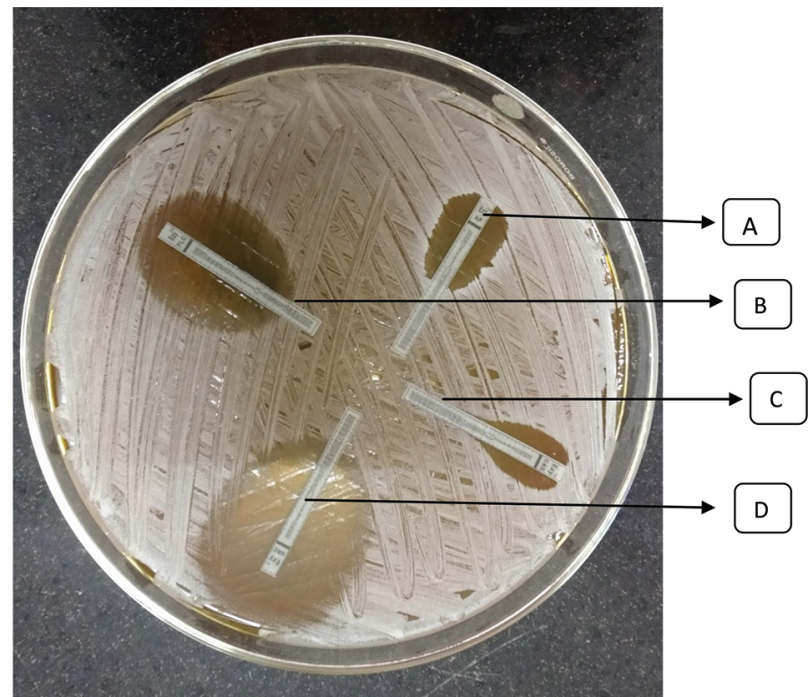

A- Amphotericin B ; B-Fluconazole; C-Caspofungin ; D-Voriconazole

Fig. 5 Antifungal susceptibility testing by E-test method.

voriconazole $17 / 90$ (18.88\%) was observed in a study by Marak et $\mathrm{al}^{14}$ Another study by Yenisehirli et al, ${ }^{26}$ on antifungal susceptibility of $C$. albicans, observed 34\% resistance to fluconazole and $14 \%$ resistance to voriconazole well comparable to our study. The resistance rates derived from our study for fluconazole and voriconazole are similar to that of earlier studies. The reduced susceptibility of Candida spp. to fluconazole and voriconazole is likely due to long-term and widespread use of antifungals among the study subjects.

\section{Conclusion}

A rising trend in isolation of non-albicans Candida from urinary isolates was noticed, which was statistically significant when comparing catheterized and noncatheterized urinary isolates from our study. However, there was no statistically significant difference when different virulence factors expressions were compared among Candida spp. isolated from catheterized and noncatheterized urinary samples. Isolation of Candida in urine is often ignored as a commensal or a contaminant and therapeutic intervention to patients 
with candiduria always needs to be individualized considering the underlying risk factors, extent of the disease and renal function, to arrest further dissemination of infections. Due to the advent of non-albicans Candida species causing UTIs that are intrinsically resistant to certain antifungal agents like azoles and increasing incidence of antifungal resistance, it is essential to monitor the antifungal susceptibility profile of Candida species causing candiduria. More studies on the relevance of virulence factors of Candida are needed to further understand the pathogenesis of candidiasis and also to guide the exploration of new antifungal drug targets to ensure better outcomes for patients as mortality with candiduria can be high in debilitated patients and those in advanced age.

\section{Approval}

This study was done after approval by Institutional Human Ethical Committee.

\section{Conflict of Interest}

None declared

\section{References}

1 Kauffman CA, Fisher JF, Sobel JD, Newman CA. Candida urinary tract infections-diagnosis. Clin Infect Dis 2011;52(suppl 6) :S452-S456

2 Agarwal S, Manchanda V, Verma N, Bhalla P. Yeast identification in routine clinical microbiology laboratory and its clinical relevance. Indian J Med Microbiol 2011;29(2):172-177

3 Larone DH, Medically Important Fungi: A Guide to Identification. 5th ed. Washington DC: ASM press; 2011

4 Tsang CSP, Chu FCS, Leung WK, Jin LJ, Samaranayake LP, Siu SC. Phospholipase, proteinase and haemolytic activities of Candida albicans isolated from oral cavities of patients with type 2 diabetes mellitus. J Med Microbiol 2007;56(Pt 10) :1393-1398

5 Samaranayake LP, Raeside JM, MacFarlane TW. Factors affecting the phospholipase activity of Candida species in vitro. Sabouraudia 1984;22(3):201-207

6 Mohandas V, Ballal M. Distribution of Candida species in different clinical samples and their virulence: biofilm formation, proteinase and phospholipase production: a study on hospitalized patients in southern India. J Glob Infect Dis 2011;3(1):4-8

7 Staib F. Serum-proteins as nitrogen source for yeastlike fungi. Sabouraudia 1965;4(3):187-193

8 Manns JM, Mosser DM, Buckley HR. Production of a hemolytic factor by Candida albicans. Infect Immun 1994;62(11):5154-5156

9 Branchini ML, Pfaller MA, Rhine-Chalkberg J, Frempong T, Isenberg HD. Genotype variation and slime production among blood and catheter isolates of $C$. parapsilosis. J Clin Microbiol 1994;32:452-456
10 Clinical and Laboratory Standards Institute, Method for Antifungal Disk Diffusion Susceptibility Testing of Yeasts. 3rd ed. CLSI document M44. Wayne, PA: Clinical and Laboratory Standards Institute; 2020

11 Lundstrom T, Sobel J. Nosocomial candiduria: a review. Clin Infect Dis 2001;32(11):1602-1607

12 Guler S, Ural O, Findik D, Arslan U. Risk factors for nosocomial candiduria. Saudi Med J 2006;27(11):1706-1710

13 Gharanfoli A, Mahmoudi E, Torabizadeh R, Katiraee F, Faraji S. Isolation, characterization, and molecular identification of Candida species from urinary tract infections. Curr Med Mycol 2019;5(2):33-36

14 Marak MB, Dhanashree B; Isolated from Clinical Samples. Antifungal susceptibility and biofilm production of Candida spp. Int J Microbiol 2018;2018:7495218

15 Sajjan AC, Mahalakshmi VV, Hajare D. Prevalence and antifungal susceptibility of Candida species isolated from patients attending tertiary care hospital. IOSR J Dent Med Sci 2014;13(5):44-49

16 Passos XS, Sales WS, Maciel PJ, et al. Candida colonization in intensive care unit patients' urine. Mem Inst Oswaldo Cruz 2005;100(8):925-928

17 Tomczak H, Szałek E, Grześkowiak E. The problems of urinary tract infections with Candida spp. aetiology in women. Postepy Hig Med Dosw 2014;68:1036-1039

18 Jain M, Dogra V, Mishra B, Thakur A, Loomba PS, Bhargava A. Candiduria in catheterized intensive care unit patients: emerging microbiological trends. Indian J Pathol Microbiol 2011;54(3):552-555

19 Lata RP, Jayshri DP, Palak B, Sanjay DR, Parul DS. Prevalence of Candida infection and its antifungal susceptibility pattern in tertiary care hospital, Ahmedabad. Natl J Med Res 2012;2:439-441

20 Achkar JM, Fries BC. Candida infections of the genitourinary tract. Clin Microbiol Rev 2010;23(2):253-273

21 Schaller M, Borelli C, Korting HC, Hube B. Hydrolytic enzymes as virulence factors of Candida albicans. Mycoses 2005;48(6):365-377

22 Alenzi FQB. Virulence factors of Candida species isolated from patients with urinary tract infection and obstructive uropathy. Pak J Med Sci 2016;32(1):143-146

23 Borst A, Fluit AC. High levels of hydrolytic enzymes secreted by Candida albicans isolates involved in respiratory infections. J Med Microbiol 2003;52(Pt 11) :971-974

24 Sachin CD, Ruchi K, Santosh S. In vitro evaluation of proteinase, phospholipase and haemolysin activities of Candida species isolated from clinical specimens. Int J Med Biomed Res 2012;1(2):153-157

25 Udayalaxmi JS, Jacob S, D'Souza D. Comparison between virulence factors of Candida albicans and non-Albicans species of Candida isolated from genitourinary tract. J Clin Diagn Res 2014;8(11):DC15-DC17

26 Yenisehirli G, Bulut N, Yenisehirli A, Bulut Y. In vitro susceptibilities of Candida albicans isolates to antifungal agents in Tokat, Turkey. Jundishapur J Microbiol 2015;8(9):e28057 